\title{
A case report of Turner syndrome associated with fetal nuchal cystic hygroma and bilateral syndactyly of the hands and feet
}

\author{
Hai-Ying Chen, Jian-Qiong Zheng and Hong-Ping Zhang*
}

\begin{abstract}
Background: Turner syndrome $(45, X)$, accounts for $1-2 \%$ of conceptions which typically miscarry early in the first trimester. Cases detected prenatally often present with cystic hygroma, which is an ultrasound marker for aneuploidy generally, but Turner syndrome particularly. In this study, we report a second trimester intrauterine fetal demise (IUFD), complicated by a marked cystic hygroma and bilateral syndactyly of the fingers and toes.

Case presentation: A 25-year-old woman presented for her first prenatal visit at 22-week gestation with IUFD. Color Doppler ultrasound revealed a septated nuchal lymphatic hygroma and hydrops fetalis, characterized by edema of the whole body, substantial pleural effusion and abdominal fluid. Pregnancy was further complicated by oligohydramnios. Following labor induction, a stillborn female baby was delivered at 22 weeks gestation. Autopsy confirmed the presence of huge nuchal cystic hygroma $(10 \mathrm{~cm} \times 10 \mathrm{~cm} \times 6 \mathrm{~cm})$ and generalized edema. Bilateral, partial syndactyly involving digits 2-5 of the fingers and toes were also observed. Chromosomal analysis revealed a 45,X karyotype.

Conclusions: We investigated an unusual case of severe septated nuchal cystic hygroma associated with bilateral syndactyly of the fingers and toes in a stillborn infant with Turner syndrome. Although cystic hygroma has been frequently reported in $45, X$ the severity is marked in this case. In addition, syndactyly is not a typical complication of Turner syndrome. This case emphasizes the importance of early ultrasound in pregnancy.
\end{abstract}

Keywords: Turner syndrome, Nuchal cystic hygroma, Syndactyly

\section{Background}

Redenbacher first described cystic hygroma in 1828 which is found in $1.0 \%$ of transvaginal ultrasound by firsttrimester or early midtrimester [1]. Cystic hygroma is a macrocystic lymphatic malformation found in the posterior triangle between the neck and axilla in $75 \%$ of cases [2]. Cystic hygroma is regarded as an important marker for aneuploidy generally including trisomies but is a particularly common in Turner syndrome [3]. In fact the observation of cystic hygroma on ultrasound is attributable to Turner syndrome in $30-70 \%$ of cases [4]. Turner syndrome is one of the most common chromosomal disorders, thought to

\footnotetext{
* Correspondence: zjzhp@126.com

Department of Obstetrics and Gynecology, Wenzhou People's Hospital, Wenzhou Maternal and Child Health Care Hospital, The Third Clinical Institute Affiliated To Wenzhou Medical University, Wenzhou 325000, China
}

occur in $1-2 \%$ of all pregnancies, accounting for $10 \%$ of all spontaneously fetal loss and 99\% of all Turner syndrome conceptions are believed to miscarry [5]. The frequency of the condition in female newborns is approximately 1 in 2500 [6]. When diagnosed in the newborn period, Turner syndrome presents with puffiness of the hands and feet or redundant nuchal skin. They may also present with cardiac anomalies such as hypoplastic left heart or coarctation of the aorta. Most commonly, however, Turner syndrome presents later in childhood as short stature, or in adolescence when they fail to enter puberty [7].

In this study, we report an IUFD case of a fetus with Turner syndrome presenting at 22 weeks gestation with profound cystic hygroma and hydrops fetalis. Syndactyly of the fingers and toes was also observed. Written informed consent from the parents was obtained for this publication. 


\section{Case presentation}

A 25-year-old pregnant woman presented for her first prenatal appointment to the outpatient Department of Obstetrics at 22 week gestation. She was primigravida (G1P0) and reported an uneventful pregnancy prior to that point. She had not had any previous ultrasounds. Obstetric examination failed to detect a fetal heartbeat. Color Doppler ultrasound revealed nuchal lymphatic hygroma of about $62 \times 99 \times 103 \mathrm{~mm}$ and hydrops fetalis (Fig. 1a). Additionally, substantial pleural effusion and
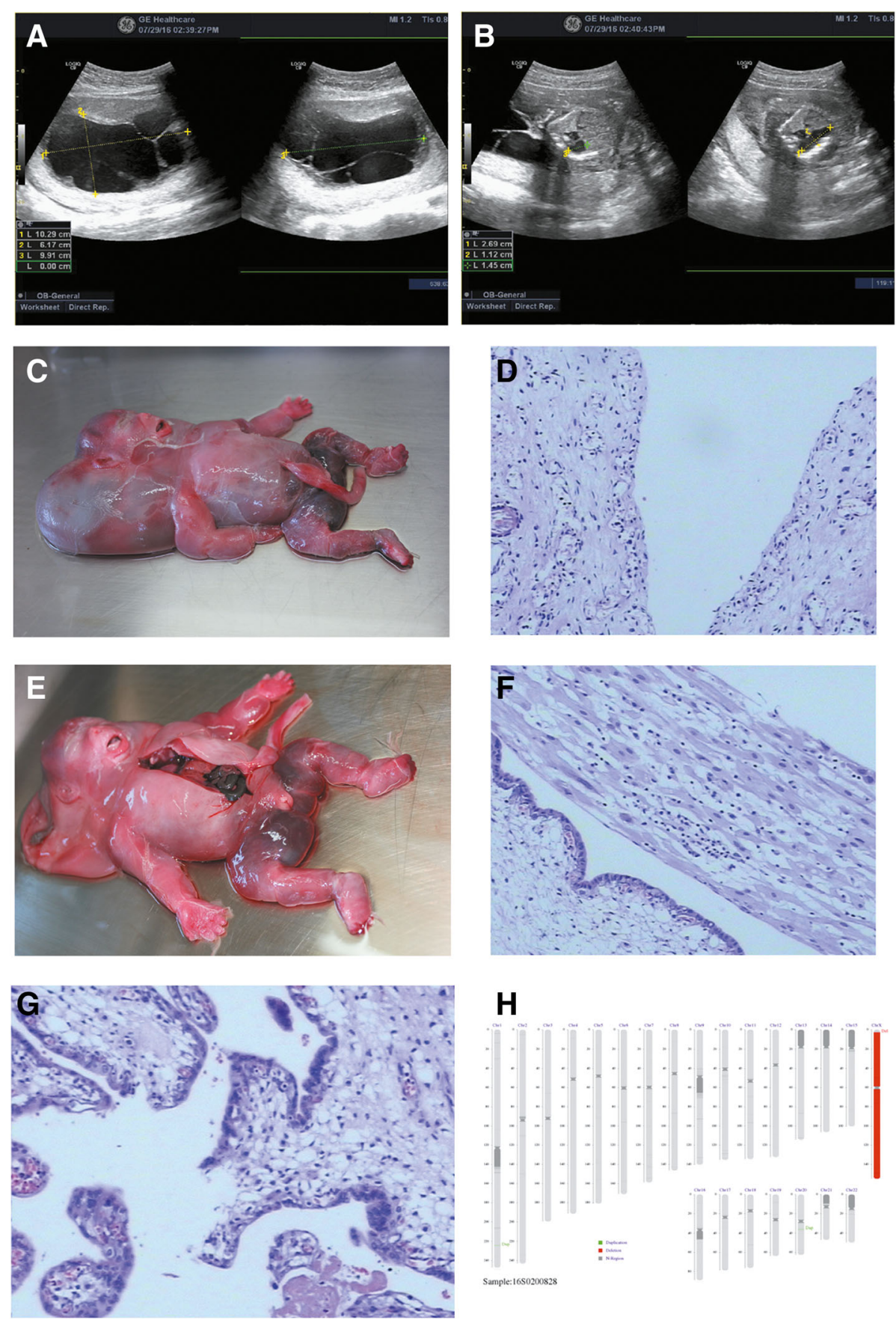

Fig. 1 Clinical, histological and genetic observations. a Color Doppler ultrasound revealed nuchal lymphatic hygroma of about $62 \times 99 \times 103 \mathrm{~mm}$ as characterized by pathognomonic edema of the whole body. $\mathbf{b}$ Substantial pleural effusion and abdominal fluid of the fetus were also observed. c, d Autopsy data showed a huge nuchal cystic hygroma measured at $10 \times 10 \times 6 \mathrm{~cm}$. e Webbed fingers and toes were also observed at autopsy. $\mathbf{f}$, $\mathbf{g}$ pathological examination revealed severe placental chorioamnionitis. $\mathbf{h}$ Chromosomal karyotype analysis of the fetal buttock muscle tissue showed chromosome $X$ deletion (45X) 
abdominal fluid of the fetus were also observed (Fig. 1b). Furthermore, the pregnancy was also complicated by oligohydramnios (AFV $11 \mathrm{~mm}$ ). Upon inducing labor, a stillborn female baby was delivered at 22 weeks and 2 days of gestation, which weighed $600 \mathrm{~g}$ and the crown to heel measurement was $27 \mathrm{~cm}$ long (50th centile). Autopsy data showed a huge nuchal cystic hygroma measured at $10 \times 10 \times 6 \mathrm{~cm}$ (Fig. 1c, d), including $1000 \mathrm{ml}$ of light red fluid, along with pathognomonic edema of the whole body. Partial, cutaneous syndactyly involving digits $2-5$ of the fingers and toes were also observed on autopsy but, unfortunately, were not photographed clearly and radiographs were not performed. In addition, pathological examination revealed severe placental chorioamnionitis (Fig. 1f, g). Of note, no structural anomaly was found in the heart, lungs and kidneys. Chromosomal karyotype analysis of the fetal tissue showed monosomy $\mathrm{X}(45, \mathrm{X})$ (Fig. 1h).

\section{Discussion and conclusions}

Cystic hygroma is a cystic lymphangioma frequently observed in soft tissues, such as neck (75\%), axillae (20\%), and retroperitoneum (5\%) [2]. When detected on ultrasound, there is a high a priori probability of the fetus having Turner syndrome [4]. This was the case in the fetus reported who had a karyotype of $45, \mathrm{X}$. This case also presented with oligohydramnios and intrauterine fetal demise (IUFD), both of which are common complications of Turner syndrome $[4,8]$. Turner syndrome is often associated with cardiac anomalies, renal deformity and low-set ears, none of which were detected in this case. This may reflect the variability of these features or the fact that a clinical geneticist did not examine the fetus. Of note, partial, cutaneous syndactyly of the fingers and toes has only rarely been reported in association with Turner syndrome, 45,X $[9,10], 45, \mathrm{X} / 46, \mathrm{Xr}(\mathrm{X}), 45, \mathrm{X} / 46, \mathrm{XY}[11]$. The syndactyly in this case may be caused by haploinsufficiency related to the 45 , X karyotype though this is unlikely due to the rarity of the association. It is more plausibly caused by functional hemizygosity of a mutation on the remaining X chromosome. This is plausible given that isolated and syndromic syndactyly have been reported in association with Xchromosome genes. Alternatively it may be unrelated. Unexpectedly, serious placental infection, chorioamnionitis was detected by pathological examinations. However, it is unclear whether chorioamnionitis was associated with fundus disease and thus could have contributed to IUFD.

In this study, we report a case of Turner syndrome presenting with an unusually severe cystic hygroma and syndactyly of the fingers, toes. This case highlights the importance of a first trimester ultrasound which would have almost certainly have detected an increased nuchal translucency in this case and spared the mother the distress of an unexpected IUFD at 22 weeks gestation. It also adds another rare report of syndactyly in association with Turner syndrome. This study highlights the importance of ultrasound in late first trimester or early second trimester in recognizing unusual cases of severe aneuploidy presentations prior to IUFD late in the second trimester.

\section{Abbreviation \\ IUFD: intrauterine fetal demise}

\section{Acknowledgements}

Not applicable.

Authors' contributions

All authors cared for, and clinically evaluated, the patient. HYC, JQZ and HPZ wrote the report. All authors read and approved the final manuscript.

\section{Funding}

Not applicable.

Availability of data and materials

All included.

Ethics approval and consent to participate

The study was approved by the ethic committee. Informed consent was obtained.

Consent for publication

Consent to publication was obtained.

\section{Competing interests}

The authors declare that they have no competing interests.

Received: 5 May 2019 Accepted: 12 July 2019

Published online: 18 July 2019

\section{References}

1. Bronshtein M, Rottem S, Yoffe N, Blumenfeld Z. First-trimester and early second-trimester diagnosis of nuchal cystic hugroma by transvaginal sonography:diverse prognosis of the septated from the nonseptated lesion. cular colobomata. Am J Obstet Gynecol. 1989:161(1):78-82.

2. Giacalone PL, Boulot P, Deschamps F, Hedon B, LaVargue F, Viala JL. Prenatal diagnosis of cavernous lymphangioma of the arm. Ultrosound Obstet Gynecolr. 1993;30:413-24.

3. Yoshida S, Miura K, Yamasaki K, Miura S, Shimada T, Tanigawa T, Yoshida A, Nakayama D, Masuzaki H. Does increased nuchal translucency indicate a fetal abnormality? A retrospective study to clarify the clinical significance of nuchal translucency in Japan. J Hum Genet. 2008;53:688-93.

4. Alpman A, Cogulu O, et al. Prenatally diagnosed turner syndrome and cystic hygroma: incidence and reasons for referrals. Fetal Diagn Ther. 2009;25(1): 58-61.

5. Urbach A, Benvenisty N. Studying early lethality of $45, \mathrm{XO}$ (Turner's syndrome) embryos using human embryonic stem cells. PLoS One. 2009; 4(1):e4175.

6. Reindollar RH. Turner syndrome:contenmporary thoughts and reproductive issues. Semin Reprod Med. 2011;29:342.

7. Sybert VP, McCauley E. Turner's syndrome. N Engl J Med. 2004;351(12):1227-38.

8. Gembruch U, Hansmann M, Bald R, Zerres K, Schwanitz G, Födisch HJ. Prenatal diagnosis and management in fetuses with cystic hygromata colli. Eur J Obstet Gynecol Reprod Biol. 1988;29(4):241-55.

9. Conen PE, Hampole MK, Thomson HG. Chromosome abnormalities in patients with syndactyly. Can Med Assoc J. 1969;101(10):75-8.

10. Kushnick $T$, Irons TG, et al. $45 \mathrm{X} / 46 \mathrm{X}, \mathrm{r}(\mathrm{X})$ with syndactyly and severe mental retardation. Am J Med Genet. 1987;28(3):567-74

11. Akbas $E$, Soylemez $F$, et al. Analysis of the SRY gene in a girl with $45, X / 46, X Y$ genotype. Genet Couns. 2009;20(3):249-54.

\section{Publisher's Note}

Springer Nature remains neutral with regard to jurisdictional claims in published maps and institutional affiliations. 